\title{
The Health Consequences of Second-Hand Smoke Exposure on Asthma and Respiratory Health of School Children in Jordan
}

\author{
Nahla AL Ali ${ }^{1, *}$, Zaid Alhamdan ${ }^{1}$, Najwa Almughrabi ${ }^{2}$ \\ ${ }^{1}$ Department of Community and Mental Health, Faculty of Nursing ,Jordan University of Science and Technology \\ ${ }^{2}$ Madinah Cardiac Center, Kingdom of Saudi Arabia \\ *Corresponding Author: nmali@just.edu.jo
}

Copyright $(2015$ Horizon Research Publishing All rights reserved.

\begin{abstract}
This survey sought to measure the respiratory health effects and the prevalence of second-hand smoke exposure among school children. A sample of 370 parents selected from primary health care centres in Zarqa governorate, Jordan. International Study of Asthma and Allergies in Childhood (ISAAC) questionnaire was used to gather the data. Descriptive statistics, Person correlation coefficient, and Pearson Chi-Square were used to analyse the data. The prevalence of "at home" exposure was 3.82 hours/day. The main location for exposure was at home $(22.1 \%)$, with the homes of others $(17.3 \%)$ and the in vehicle exposure (14.3\%) being the next two most commonly cited indoor locations. A significant association was found between exposure to second-hand smoke at home, indoors-other, in vehicles, and in the restaurants and other recreational areas, and asthma and rhinitis symptoms. The number of rooms and people per room, parents' educational achievement were also associated with respiratory symptoms of children. These results shed light on the importance to protect children from the harm of smoking and to carry out home smoke free policy.
\end{abstract}

Keywords Second-Hand Smoke, Exposure, Children, Respiratory Symptom, Asthma, Rhinitis, Jordan

\section{Introduction}

The impact of smoking in the population has become a growing concern throughout the world. Secondhand smoke (SHS) exposure, even it is preventable, remains a major public health concern [1], and is considered one of the most air pollutants with many adverse health effects [2]. World Health Organization claimed that the majority of children exposed to tobacco smoke against their choice. Children's exposure is involuntary, arising from smoking mainly by adults, in places where children exist, study, and play [3]. Secondhand smoke is a mixture of gases and fine particles that includes smoke from a burning tobacco side stream smoke (cigarettes, pipe, or cigar) and mainstream smoke (smoke that exhaled by smokers). It includes more than 7, 000 chemicals, including hundreds that are toxic and about 70 that can cause cancer [4]. Half of the children in the world are exposed to SHS, mostly in their homes. This high level of exposure, coupled with the evidence that SHS causes illness in children, and suggests an extensive public health warning for children [3]. Globally, about one-third of adults are regularly exposed to second-hand tobacco smoke [3]. According to the Global Youth Tobacco Survey (GYTS), 43\% of children at least have one smoking parent. Data from the GYTS show that among those surveyed, nearly half of youth aged 13 to 15 years who have never smoked exposed to second-hand tobacco smoke in the home, with a similar percentage exposed in places other than the home; these youth are 1.5 to 2 times more likely to start smoking than those not exposed [5]. A study among a sample of 220 infants and mothers attending an outpatient pediatric clinic, found that $60 \%$ of the infants exposing to SHS and $36.4 \%$ of the infants had detectable levels $(7.1 \mathrm{ng}$ / $\mathrm{mg}$ ) of urine cotinine. The study also found cotinine in saliva among eight of the 20 mothers with neonates (1-2 days old), implying in-utero SHS exposure [6].

Giving the reason that children are unable to avoid the main source of exposure [7], second-hand smoke causes many symptoms, ear infections, severe asthma attacks, respiratory symptoms (e.g., coughing, sneezing, shortness of breath), respiratory infections (i.e., bronchitis, pneumonia), and increase a risk for sudden infant death syndrome (SIDS). Some of these problems can become serious and life-threatening $[4,8]$. This exposure causes 600,000 premature deaths $(28 \%$ are children $)$ worldwide [3]. Further, the estimates of attributes risk of household SHS exposure in children ranged from $9 \%$ for asthma prevalence to $25 \%$ of hospital admissions due to respiratory symptoms [9].

Passive or active exposure to tobacco smoke, was the most constant connection in the etiology of asthma [10]. 
Mainstream and side stream tobacco smoke are well identified for their capacity to stimulate inflammatory responses that are relevant to the immune pathogenesis of asthma, and the incidence and the return of wheezing in early life are increased if there is smoke in the home [11].

The home is the main place for smoking, where many children exposed to tobacco smoke in their daily lives, while eating, entertaining, and even sleeping. Secondhand smoke exposure also continues to occur in public places such as restaurants, shopping centres, public transportation, schools, and day care centres $[9,12]$. However, unlike adults, children inhale more of the toxic chemicals in smoke per unit body weight because they breathe faster and are generally more physically active. They may also be less able to metabolize and excrete certain toxic components of SHS, so these components stay in the body for longer periods of time [3].

In Jordan overall rate of smoking is $29 \%$ ( $50 \%$ are men). Of the 11,885 families in Jordan, $61 \%$ have a continuing smoker in the home [13]. The prevalence of SHS among Jordanian non-smoker adults was $24.5 \%$, and $40 \%$ among children [8]. Unfortunately, few studies investigating SHS exposure among school aged children and the adverse health effect of this exposure. Although, there is an initiative and legislative ban on public smoking, still exposure to SHS is highly prevalent [14]. Thus, the current study will offer primary data about the prevalence of SHS exposure among school aged children, and will address the existing gap by measuring SHS exposure among school aged children and its impact on their respiratory health. This information is important to carry out smoke free environment, and shed the light on the health consequences of SHS exposure on respiratory health of children. The results will also help nurses and other health care professionals to develop and design health promotion and education program to increase knowledge of parents and to change their attitudes toward smoking to protect their children.

The purpose of this study was to examine the health consequences of Secondhand smoke exposure on asthma and respiratory symptoms, and to assess the prevalence of indoor Second-hand smoke exposure of Jordanian school-aged children.

\section{Materials and Methods}

\subsection{Design of the Study and the Sample}

A descriptive, cross-sectional design employed in this study. Purposive/Convenience sampling was used.

A convenient sample of parents (mothers or fathers); who have at least one smoker in the home; and having children aged from 6-11 years invited to take part in this study. Parents approached during their visits to any comprehensive health care centre in Zarqa city. Zarqa governorate is the third largest metropolitan population in Jordan, located about $20 \mathrm{~km}$ east from Amman the capital, with around 916950 persons and a population density of 191.3 persons per Km [13]. Only the comprehensive health care centres were selected because it served many of the populations.

\subsection{Procedure}

After approval was obtained from the directors of the selected health care centres, the principal investigator approached the parents in the waiting room, explains to them the purpose of the study and invited them to take part. Parents who agreed to take part were asked to sign a consent form, and then invited to a private room where they can respond to the questionnaire.

\subsection{Measures}

The prevalence of SHS exposure of children was measured using self-reported exposure to passive smoke at home and at the other micro-environment places (other persons' home, in vehicles, restaurants and other locations) as independent variables after adjusting for child' age, gender, and socioeconomic status as well as exposure to dust and/or gases and pets.

An open-ended question adapted from Gharaibeh et al., to measure the "at home" exposure "How many hours in a day your child is usually exposed to SHS?" [15]. A validated survey instrument was used to measure self-reported recent SHS exposure during the previous 7 days in four micro-environments: at the respondent's home, another person's home, travelling in a car or other vehicle (including outdoor smoking areas), and other locations (Restaurant, recreational areas). The prevalence of SHS exposure in these places was calculated in terms of the percentage of positive responses to each question divided by the number of completed questionnaires.

A modified version of the International Study of Asthma and Allergies in Childhood (ISAAC) questionnaire was used to measure the respiratory health consequences of SHS exposure on children [16]: The prevalence of all respiratory symptoms (asthma \& rhinitis) was calculated in terms of the percentage of positive responses to each question divided by the number of completed questionnaires.

Asthma was defined as wheezing or whistling symptoms during the last 12 months without having a cold, and was measured as a positive response to at least one of the following questions:

1. Has your child ever had wheezing or whistling in the chest at any time in the past? (Wheezing ever)

2. Has your child ever had asthma? (Asthma ever)

3. Has your child had wheezing or whistling in the chest in the last 12 months?. (Wheezing)

4. How many attacks of wheezing has your child had in the last 12 months? ( $\geq 4$ attacks of wheezing)

5. In the last 12 months, how often, on average, has your child's sleep been disturbed due to wheezing? 
(Wheezing during sleep)

6. In the last 12 months, has wheezing ever been severe enough to limit your child's speech to only one or two words at a time between breaths? (Severe wheezing)

7. In the last 12 months, has your child had a dry cough at night not associated with a cold or chest infection? (Night cough)

8. In the last 12 months, has your child's chest sounded wheezy during or after exercise? (Exercise wheeze)

Rhinitis was defined as the existence of problem with sneezing, or a runny, or blocked nose during the last 12 months without having a cold, and measured by positive response to the following questions:

1. Have your child ever had a problem with sneezing, or a runny, or blocked nose when he/she did not have a cold or the flu? (Nose symptoms ever)

2. Has your child ever had hay fever? (Hay fever ever)

3. Has your child had a problem with sneezing, or a runny, or blocked nose when he/she did not have a cold or the flu in the last 12 months?). (Nose symptoms)

4. In the past 12 months, had this nose problem has been accompanied by itchy-watery eyes? (Itchy-watery eyes)

5. In the past 12 months, how much did this nose problem interfere with your child's daily activities? (Activities limited)

The questionnaire also includes demographic characteristics of the parents; smoking habits of mother and father; respiratory and general health of the child; and, home characteristics such as the presence of mould/dampness, and pets. The instrument is supported for construct validity; Cronbach's alpha scores (0.87-0.95).

\subsection{Ethical Approval}

Ethical approval was obtained from the Scientific Research Committee at Jordan University of Science and Technology. Approval from Ministry of Health and permission was also obtained. Informed consent was obtained from each participant after the investigator had explained the nature, and the purpose of the study. Parents were assured that their participation was entirely voluntary, and they have the right to withdraw or refuse to give information at any time during the study without any penalties. Confidentiality of the data provided and strictly maintained.

\subsection{Data Analysis}

Statistical package for social science (SPSS), version 17 was used to analyse the data [17]. Descriptive statistics (means, standard deviations, frequencies, and percentages) were used to describe the socio-demographics and the individual items. Person correlation coefficient and Pearson Chi-Square were used to assess the association of SHS exposures with asthma, and rhinitis symptoms.

\section{Results}

\subsection{Participants}

A total of 400 parents participated in this study, 370 were completed the survey and 30 parents were withdrawn from the study for personal reasons not related to the study. Of 370 parents, $70 \%$ were mothers $(n=259)$. Mean age of parents was 35.8 years $(\mathrm{SD}=7.05$ years $)$, and the mean age of children was 8.1 years $(\mathrm{SD}=1.7$ years). The Mean number of rooms per home was 3.13 rooms $(\mathrm{SD}=1.08)$, while the average number of people per room per home was $2.69(\mathrm{SD}=1.39)$ person.

Table 1. Demographic Characteristics of the Participants $(\mathrm{N}=370)$

\begin{tabular}{|c|c|c|}
\hline Item & Category & $\mathrm{N}(\%)$ \\
\hline \multirow{2}{*}{ Participants } & Mother & $259(70 \%)$ \\
\hline & Father & $111(30 \%)$ \\
\hline \multirow{4}{*}{ Mother educational level } & No education & $30(8.1 \%)$ \\
\hline & $\begin{array}{l}\text { Primary \& } \\
\text { elementary }\end{array}$ & $70(18.9 \%)$ \\
\hline & High school & $151(40.8 \%)$ \\
\hline & University & $87(32.2 \%)$ \\
\hline \multirow{4}{*}{ Father educational level } & No education & $26(7.0 \%)$ \\
\hline & $\begin{array}{l}\text { Primary \& } \\
\text { elementary }\end{array}$ & $89(24.1 \%)$ \\
\hline & High school & $125(33.8 \%)$ \\
\hline & University & $130(35.1 \%)$ \\
\hline \multirow{3}{*}{ Smoking status of parents } & Yes (in house) & $228(61.6 \%)$ \\
\hline & Yes (outside house) & $59(15.9 \%)$ \\
\hline & No & $83(22.4 \%)$ \\
\hline \multirow{3}{*}{ Family member smoking status } & No & $274(74.1 \%)$ \\
\hline & Yes (outside house) & $32(8.6 \%)$ \\
\hline & Yes (in house) & $64(17.3 \%)$ \\
\hline \multirow{2}{*}{$\begin{array}{l}\text { Smoking in the presence of } \\
\text { children }\end{array}$} & Always & $303(81.9 \%)$ \\
\hline & Never & $67(18.1 \%)$ \\
\hline
\end{tabular}

Of all parents, $66.4 \%(n=172)$ of mothers and $63.1 \%$ $(n=70)$ of fathers had school educational achievement. Half of participating parents were smokers $(51.1 \%, \mathrm{n}=189)$, $61.6 \%(n=228)$ of the parents were smoking inside the home, and $81.9 \%(n=303)$ always smoked in the presence of children (Table 1).

Almost $85.1 \%(n=315)$ of the parents never had pets. While the majority of the parents had a gas cooker $(92.7 \%$, $\mathrm{n}=343)$ and had a gas heater $(78.6 \%, \mathrm{n}=291)$. Of all parents, $75.4 \%(n=279)$ had not seenmould/dampness/fungi in the first year of child's age. Around $75.4 \%(n=279)$ of parents reported having parents or siblings with a history of asthma or eczema or high fever 


\subsection{The Prevalence of Second-hand Smoke Exposure among Children}

The results of Second-hand smoke exposure among children in the past 7 days "at home" was 3.82 hours/day $(\mathrm{SD}=2$. 4hours). The location of SHS exposure is presented in Table 2. At home $(22.1 \%)$ is the main location for exposure, with the homes of others $(17.3 \%)$ and the in vehicle exposure $(14.3 \%)$ being the next two most commonly cited indoor locations.

Table 2. Positive responses to the questions about the current exposure in the past 7 days $(\mathrm{N}=370)$

\begin{tabular}{|l|l|l|}
\hline \multicolumn{1}{|c|}{ Items } & \multicolumn{1}{|c|}{$\begin{array}{c}\text { Positive responses } \\
\mathrm{N}(\%)\end{array}$} & $\begin{array}{c}\text { Prevalence of } \\
\text { exposure }\end{array}$ \\
\hline $\begin{array}{l}\text { Smoking in the presence of } \\
\text { children at home }\end{array}$ & $303(81.9)$ & $22.1 \%$ \\
\hline $\begin{array}{l}\text { Smell tobacco smoke in another } \\
\text { person's house }\end{array}$ & $238(64.3 \%)$ & $17.3 \%$ \\
\hline $\begin{array}{l}\text { Travelled by car or other vehicle } \\
\text { with someone else who was } \\
\text { smoking tobacco products }\end{array}$ & $197(53.2 \%)$ & $14.3 \%$ \\
\hline $\begin{array}{l}\text { Being in a restaurant, sports area, } \\
\text { or other place of entertainment } \\
\text { where someone else was smoking } \\
\text { tobacco products. }\end{array}$ & $80(21.6 \%)$ & $5.8 \%$ \\
\hline
\end{tabular}

\subsection{The Prevalence of Respiratory Symptoms (Wheezing and Rhinitis)}

The cumulative and current prevalence of parents' response to the items associated with wheezing and rhinitis module is shown in Tables 3 and 4. For the wheezing module, the cumulative prevalence for "ever- wheezed" was $16.2 \%$. The diagnosed asthma prevalence was, only $6.6 \%$. The prevalence of wheezing symptoms in the last 12 months were, $38 \%$ for current wheezing, $32.2 \%$ night wheezing, and $19.4 \%$ severe wheezing. Night cough was $17.5 \%$, and exercised induced wheezing was $10.3 \%$. The prevalence of $\geq 4$ wheezing attacks was $12.6 \%$.
Table 3. Percent of positive responses to questions about the wheezing symptoms

\begin{tabular}{|l|l|}
\hline \multicolumn{1}{|c|}{ Symptoms } & \multicolumn{1}{|c|}{ Prevalence of wheezing symptoms } \\
\hline Wheezing ever & $16.2 \%$ \\
\hline Asthma ever & $6.6 \%$ \\
\hline \multicolumn{2}{|c|}{ Symptoms in the last 12 months } \\
\hline Wheezing & $37.9 \%$ \\
\hline Severe wheezing & $19.4 \%$ \\
\hline Night cough & $17.5 \%$ \\
\hline Exercise wheeze & $10.3 \%$ \\
\hline Wheeze during sleep & $32.2 \%$ \\
\hline$\geq 4$ attacks of wheezing & $12.6 \%$ \\
\hline
\end{tabular}

Table 4. Percent of positive responses to questions about the rhinitis symptoms

\begin{tabular}{|l|l|}
\hline \multicolumn{1}{|c|}{ Symptoms } & \multicolumn{1}{c|}{ Prevalence of rhinitis symptoms } \\
\hline Nose symptoms ever & $18.2 \%$ \\
\hline Hay fever ever & $22 \%$ \\
\hline \multicolumn{2}{|c|}{ Symptoms in the last 12 months } \\
\hline Nose symptoms & $36.4 \%$ \\
\hline Itchy-watery eyes & $29 \%$ \\
\hline Activities limited & $28.1 \%$ \\
\hline
\end{tabular}

For rhinitis module, the cumulative prevalence of "ever-nose symptoms" and hay fever were $18.2 \%$, and $22 \%$, respectively. Prevalence of current nose symptoms was $36.4 \%$ and $29 \%$ reported eye symptoms associated with rhinitis. Nose symptoms limited daily activities were $28.1 \%$.

Table 5. The Positive association of wheezing symptoms and exposure to SHS

\begin{tabular}{|c|c|c|c|c|}
\hline Symptoms & "at home" & Indoors-other & In vehicles & $\begin{array}{c}\text { Restaurant } \\
\text { And other recreational areas }\end{array}$ \\
\hline Wheezing ever & $\mathrm{X}^{2}(1)=15.313, p=.000$ & - & - & - \\
\hline Asthma ever & - & $X^{2}(1)=5.689, p=.017$ & $\mathrm{X}^{2}(1)=13.391, p=.000$ & - \\
\hline \multicolumn{5}{|c|}{ Symptoms in the last 12 months } \\
\hline Wheezing & & - & $\mathrm{X}^{2}(1)=7.036, p=.009$ & - \\
\hline Severe wheezing & & - & - & - \\
\hline Night cough & $X^{2}(1)=10.502 p=.002$ & $X^{2}(1)=8.232, p=.005$ & $\mathrm{X}^{2}(1)=15.807, p=.000$ & \\
\hline Exercise wheeze & $\mathrm{X}^{2}(1)=12.456, p=.000$ & - & - & - \\
\hline Wheeze during sleep & & - & - & - \\
\hline$\geq 4$ attacks of wheezing & & - & - & - \\
\hline
\end{tabular}


Table 6. The Positive association of the rhinitis symptoms and exposure to SHS

\begin{tabular}{|c|c|c|c|c|}
\hline Symptoms & "at home" & Indoors-other & In vehicles & $\begin{array}{c}\text { Restaurant } \\
\text { And other recreational areas }\end{array}$ \\
\hline Nose symptoms ever & $\mathrm{X}^{2}(1)=18.855, p=.000$ & $\mathrm{X}^{2}(1)=6.279, \quad p=.015$ & $\mathrm{X}^{2}(1)=5.360, \quad p=.026$ & $\mathrm{X}^{2}(1)=6.083, \quad p=.015$ \\
\hline Hay fever ever & - & $\mathrm{X}^{2}(1)=4.873, \quad p=.031$ & - & - \\
\hline \multicolumn{5}{|c|}{ Symptoms in the last 12 months } \\
\hline Nose symptoms & - & - & - & - \\
\hline Itchy-watery eyes & - & $\begin{array}{c}\mathrm{X}^{2}(1)=11.210 \\
p=.001\end{array}$ & $\begin{array}{c}\mathrm{X}^{2}(1)=13.756 \\
p=.000\end{array}$ & $\mathrm{X}^{2}(1)=7.402, \quad p=.006$ \\
\hline Activities limited & - & - & - & - \\
\hline
\end{tabular}

\subsection{The Association between Secondhand Smoke Exposure and Respiratory Symptoms}

The "at home" hours exposure per day was associated significantly with only ever-wheeze symptoms $(\mathrm{r}=.137$, $\boldsymbol{p}=\mathbf{0 0 9})$, and with nose symptoms ever $(\mathrm{r}=.185, \boldsymbol{p}=\mathbf{0 0 0 0})$. Tables 5 and 6 , present the results of associations between wheezing and rhinitis symptoms and the exposure to SHS in the four micro-environments (in respondents' home, in another person's home, in vehicles, and in restaurants). For wheezing module, "at home" exposure was associated with wheezing ever, night cough and exercise wheezing. Exposure in vehicles was associated with wheezing symptoms in last 12 months, asthma ever, and night cough. "Indoors-other" exposure was associated with asthma ever, and night cough (Table 5).

Regarding rhinitis moduel, exposure to SHS in vehicles, restaurants, and "indoors-other" was associated both with the nose problem ever and the eye symptoms. Exposure "at home" was associated with the nose problem ever, and hay fever symptom was related to the "indoors-other" exposure" (Table 6).

\subsection{The Association of Respiratory Symptoms and Parents' Smoking Status}

Parents' smoking status specifically inside the home was associated with the symptoms of asthma ever $\left(X^{2}(1)=4.059\right.$, $\boldsymbol{p}=$. 044), night cough $\left(\mathrm{X}^{2}(1)=11.040, \boldsymbol{p}=\mathbf{. 0 0 1}\right)$, exercise wheeze $\left(\mathrm{X}^{2}(1)=4.715, \boldsymbol{p}=\mathbf{0 3 0}\right)$, and night wheezing $\left(X^{2}(1)=6.044, p=.014\right)$. However, there was no significant association revealed between parents' smoking status and rhinitis symptoms.

\subsection{Associations of Socio-environmental Factors and Respiratory Symptoms}

The results indicated no association between environmental characteristics (presence of the gas heater, pets, mould/dampness and fungi) and any wheezing or rhinitis symptoms. However, the number of rooms was associated significantly with wheezing ever $(\mathrm{r}=.190$, $\boldsymbol{p}=\mathbf{0 0 7})$, exercise wheeze $(\mathrm{r}=.155, \boldsymbol{p}=\mathbf{. 0 0 3})$, night wheezing $(\mathrm{r}=.251, \boldsymbol{p}=.006)$, and a weak association with night cough $(\mathrm{r}=.128, \boldsymbol{p}=.013)$. The number of people in each room was also associated with current wheezing $(\mathrm{r}=.243, \boldsymbol{p}=\mathbf{0 0 0})$, and exercise wheezing $(\mathrm{r}=.130, \boldsymbol{p}=\mathbf{0 1 2})$.
Further results regarding parents' educational level revealed a significant association between mothers and fathers' educational achievement and night wheezing symptoms $\left(\mathrm{x}^{2}(3)=11.981, \boldsymbol{p}=.018\right),\left(\mathrm{x}^{2}(3)=5.347, \boldsymbol{p}=.04\right)$, respectively.

\section{Discussion}

To our knowledge, this is the first study examined the association between SHS exposure and respiratory symptoms (wheezing and rhinitis) among school children in Jordan. Understanding the nature of the relationship between SHS and respiratory symptoms and the contributing factors is very important. Several studies indicated that exposure to SHS is one of the most common indoor pollutants [8]. The results of this study indicated that $77.5 \%$ of parents are smokers and $61.6 \%$ (either mother or father) were smoking inside home. The prevalence of exposure to SHS among children was 3.82 hours/day. This rate is higher than reported in previous study who indicated that the indoor SHS exposure for children was 3.4 hours on weekdays [18].

Although no previous studies have examined the prevalence of SHS exposure among children our results are consistent with many of existing literature in this field. A study in Jordan found that SHS exposure among nonsmoking university students was $96 \%$, the mean hour of exposure per day was 4.64 hours, and the mean days of exposure per week were 5.14 days [19]. Another study among employed women in Jordan found that mean hour SHS exposure per day was 5.5 hours, with an average of 6 days per week [15]. In this study, high rates of indoor and indoors-other SHS exposure could be explained by that smoking is deeply embedded in Jordanian culture and habits [20]. High prevalence of smoking among parents and family member who smoke inside the home and most of them do that in the presence of children, makes these children vulnerable to the harm of SHS. Giving that this age group (6-11years) spends most of their time inside the home, and if they leave their homes they joined their parents either in the car or visiting relatives, or in the restaurants. Further, in Jordan a study about parents' attitudes toward SHS exposure found that only $17.7 \%$ of women expressed that they will not let their "visitors" smoke in their home [19], because it is not acceptable to ask visitors not to smoke. However, invite 
visitors to smoke is a type of good hospitality.

Evidence suggests that vehicles can also be a significant source of SHS exposure for children. Children can be regularly exposed to SHS when parents or other adults smoke in these vehicles. The concentrations of SHS in vehicles where smoking is taking place can reach very high levels. The results of this study revealed that more than half of parents reported that their child had travelled by car or other vehicle with someone else who was smoking tobacco products. The findings of this study are consistent with other study who found that $68 \%$ of non-smokers were exposed to SHS exposure during a typical day; the most common site was in cars (57\%) [21]. A similar study found that $35 \%$ of children are exposed to SHS by their parents while in a vehicle [22]. Making vehicles smoke-free would be expected to reduce children's SHS exposure [23]. It is worth mentioning that the laws of $100 \%$ smoke-free, banning smoking in public settings, vehicles and transportation are not completely established or activated [9].

The cumulative prevalence of wheezing symptoms in our study was high for current wheezing (37.9\%), with wheezing during sleep (32.2\%), and night cough (17.5) being the next two most commonly reported symptoms. In Jordan, asthma is moderately common; this finding is illustrated by a recent study reporting that the prevalence of asthma among adolescents was $12.3 \%$ [24]. While, asthma is marked by airway inflammation and hyper responsiveness to a variety of stimuli or triggers, such as animal dander, cockroaches, dust, smoke include cigarettes or cigar smoke, moulds, stress, some types of medication, some food additives [25]. In the current study to roll out other factors such as the history of being diagnosed as asthma, and many other stimuli affecting the occurrence of asthma symptoms were included in the questionnaire (ISAAC) to elicit a true association between SHS exposure and occurrence of asthma symptoms. The results of this study indicated that there was a significant association between asthma symptoms and the average hours/day child exposed to SHS. A significant positive association was also revealed between been travelling in a car while someone was smoking tobacco and asthma symptoms, and rhinitis.

This association is congruent with the results of previous studies which found that exposure to SHS exacerbates existing asthma symptoms, and is associated with persistence wheezing to adolescence, and increased opportunity of asthma in adults [26]. A study among school children, aged 6 to 7 years and 13 to 14 years, found that maternal and paternal smoking are both independently associated with wheeze occurrence [27]. Same result revealed among students aged 9-20 years [28]. Thus, epidemiological evidence linking SHS exposure and childhood asthma is extensive [3].

Moreover, the results of this study showed a significant association between child SHS exposure in the car or other vehicle and many symptoms of Asthma (asthma ever, current wheezing, and night cough), and rhinitis (nose problem ever and eye associated symptoms). This is consistent with many of existing literature supported that child SHS exposure was definitely associated with respiratory symptoms (asthma, cough, phlegm and wheezing in children with parental smoking diseases) and childhood disease $[3,29,30]$.

The results of this study indicated that many school aged children in Jordan are exposed to SHS at home, car, other vehicle, restaurant, sports area, or other places of entertainment. Exposure to SHS in childhood has a significant association with the occurrence of respiratory symptoms (asthma, cough, and rhinitis). This is due to adults smoking in the childrens' bedrooms in the early evening, in that children are often unable to avoid the main source of exposure in their home where they spend most of their time. With their smaller airways, faster rates of breathing and immature immune systems children are also most vulnerable to any adverse health effects [31].

Studies in several countries have reported a strong relationship between socio-demographics factors and children's exposure to SHS. Among these factors are income and education, number of people in the household, having a full no-smoking rule in the home or in the car, and beliefs in SHS exposure health consequences [32].

The results of this study showed that the number of rooms was associated significantly with wheezing ever, exercise wheeze, night wheezing, and with night. The number of people in each room was also associated with current wheezing, and exercise wheezing. This result was consistent with the result of a recent study which found that the effects of SHS exposure on children's respiratory health depends also on other factors such as ventilation quality and amount of people in the room and the exact time spent in a room in which smoking has occurred [33]. Further results regarding parents' educational level revealed a significant association between mothers and fathers' educational achievement and night wheezing symptoms. This result indicated that less educated women are not fully empowered in Jordanian society [19,34], and so, it is difficult for them to restrict the father and their guests' smoking in the room. This result was consistent with the finding of another study which found that educated working women experience less SHS exposure than women with poor education or lower educational levels [35]. In the same line, a study found that exposure of preschool aged children to SHS in the home and in cars is associated with low parental education, unemployment, low household equivalent income, and family size in smoking households. Further, indoor smoking bans were less likely among those who had a low parental education, were unemployed, in poverty, single-parent family and migrants [36].

\section{Conclusions}

In this study, exposure to SHS, especially at home, and in vehicles, was associated with the prevalence of respiratory 
symptoms in children even after adjustment for other factors of exposure. In contrast to previous findings, this association was not limited to the household exposure, rather it extends to another person's house, transportations and other places where children have been vulnerable to SHS. Our study results also reflect the prevalence of respiratory symptoms among school children in Jordan.

Understanding the role of SHS in the development of childhood respiratory symptoms and infections, and exacerbations of asthma can help inform public health interventions to prevent childhood SHS exposure and the benefits of such interventions. Since children are the most susceptible group to the adverse health effects of SHS, and the bulk of their exposure occurs in the home, these results will inform health care professionals especially nurses in designing public health and education strategies to decrease the risk. The nurse in health care and community settings has the vital role in advising smokers not smoke in their own homes, and can help increase awareness to win smoke free-environment among policy makers and governmental organizations in making decisions to enforce policies for banning smoking in public places and in vehicles.

However, some limitations to the study have to be considered. Since the survey was cross-sectional, this would result in a bias toward the dose-response relationship between the daily duration of exposure and respiratory symptoms. It might be that the actual exposure has been for only a short period of time or out of doors and so the dose may have been very little or, on the contrary, there may have been several persons smoking in a relatively small space and so the exposure to SHS may have been very high during any single period.

\section{REFERENCES}

[1] US Department of Health and Human Services. A Surgeon General's report on the Health Consequences of Smoking-50 Years of Progress. Atlanta, GA: US Department of Health and Human Services, Centers for Disease Control and Prevention, Office of Smoking and Health; 2014.Web of Science ${ }^{\circledR}$ Times Cited: 13.

[2] Musk AW \& de Klerk NH. History of tobacco and health. Respirology. 2003; 8: 286-90.

[3] World Health Organization. The fact about smoking and health. Genava, Switzerland. Available from http//www.who.com. 2009. Accessed September 2013.

[4] American Cancer Society. Second Hand Smoking. Atlanta: American Cancer Society, available from: http//www.cancer.org. 2012. Accessed September 2013.

[5] David GL, Koh W-P, H-P Lee et al. Childhood exposure to environmental tobacco smoke and chronic respiratory symptoms in non-smoking adults: the Singapore Chinese Health Study. Thorax.2005; 60:1052-1058.

[6] Badran E, Salhab AS, Al-Jaghbir M. Infant exposure to environmental tobacco smoke: Jordan University hospital-based study. East.Mediterranean.Health Journal. 2009; 15: 39-46.

[7] Shafey O, Eriksen M, Ross H, Mackey J.The Tobacco Atlas. 3rd ed. Atlanta, GA: American Cancer Society; 2009.

[8] Oberg M, Jaakkola M, Woodward A, Perug A, Prüss-Ustün A. Worldwide burden of disease from exposure to second-hand smoke: retrospective analysis of data from 192 countries. The Lancet. 2011;337:139-146.

[9] Rushton L, Courage C, Green E. Estimation of the impact on children's health of environmental tobacco smoke in England and Wales. The journal of the Royal Society for the Promotion of Health.2003; 123:175-180.

[10] Kurt E, Metintas S, Basyigit, I et al. Results of a multicentric cross-sectional study in children. Pediatric Allergy Immunol. 2007; 18: 566-74.

[11] Diaz-Sanchez D, Rumold R, Gong H. Challenge with environmental tobacco smoke exacerbates allergic airway disease in human beings. J Allergy ClinImmunol. 2006; 118: 441-446.

[12] Beasley R0, Crane J, Lai CK, Pearce N. Prevalence and etiology of asthma. Allergy ClinImmunol. 2000; 105:S466-472

[13] Department of Statistics Jordan (DOS). Statistical year book 2011. Avialble from http//:www.dos.gov.jo/. 2010. Accessed September 2013.

[14] Haddad LG, Al-Zyoud S, Abu Baker N, Gharaibeh H, El Shahawy O, Alramadhani R. Secondhand Smoking in Jordan: Clearing the Air for One of the Highest Tobacco Prevalence Countries in the Middle East. Tobacco Use Insights. 2011: 4 1-7 doi: 10.4137/TUI.S6802 . This article is available from http://www.la-press.com.

[15] Gharaibeh H, Haddad L, Alzyoud S, El-Shahawy O, Abu-Baker N, Umlauf M. Knowledge, attitudes, and behavior in avoiding secondhand smoke exposure among nonsmoking employed women with higher education in Jordan. International Journal of Environmental Research and Public Health. 2011; 8 (11):4207-4219.

[16] Pearce, Neil, et al. "Worldwide trends in the prevalence of asthma symptoms: phase III of the International Study of Asthma and Allergies in Childhood (ISAAC)." Thorax . 2007; 62(9): 758-766.

[17] SPSS Inc. SPSS Statistics for Windows, Version 17.0. 2008; Chicago:SPSs.

[18] Thomson G, Wilson N, Howden PH. Smoky homes: a review of the exposure and effects of secondhand smoke in New Zealand homes. The New Zealand Medical Journal. 2005; 118 (1213): 1-11.

[19] Haddad L, Abu Baker N, El-Shahawy O, Al-Ali N, Shudayfat T. Secondhand smoke exposure among young adults in a developing country - a Jordanian case. Dove press journal. 2013. 4: 45-53.

[20] Abu Baker N, Haddad L, Savage, C. The influence of Secondhand smoke exposure on birth outcomes in Jordan. International Journal of Environmental Research and Public Health. 2010;7(2): 616-634.

[21] Hughes SC, Corocos IA, Hosftetter CR, Hovvell MF, Seo D, Irvin VL et al. Secondhand smoke exposure among 
nonsmoking adult in Seoual, Korea, Asian pacific. Journal of cancer prevention. 2008; 9: 247-252.

[22] Populus. 'Survey of 8-13 Year Olds Executive Summary' on behalf of the Department of Health Available from http://www.populus.co.uk/uploads/download_pdf-281009-Bl ue-Rubicon-Poll-of-8-13-year-oldson-smoking.pdf. 2009. Accessed October 2013.

[23] US Department of Health and Human Services. A Surgeon General's report on the health consequences of involuntary exposure to tobacco smoke. Atlanta, GA: US Department of Health and Human Services, Centers for Disease Control and Prevention, Office of Smoking and Health.2014.

[24] Al-Akour N, Khader YS. Quality of life in Jordanian children with asthma. International Journal Nursing Practice. 2008; 14(6):418-426.

[25] Lewis SA, Antoniak M, Venn AJ et al. Secondhand smoke, dietary fruit intake, road traffic exposures, and the prevalence of asthma: a cross sectional study in young children. Am J Epidemiol. 2005; 161: 406-411.

[26] Singer BC, et al. Gas-phase organics in environmental tobacco smoke. 1. Effects of smoking rate, ventilation, and furnishing level on emission factors. Environmental Science and Technology. 2002; 36:846-853.

[27] Sharma SK, Banga A. Prevalence and risk factors for wheezing in children from rural areas of north India. Allergy and Asthma Proceedings. 2007; 28:647-653.

[28] Gupta D, Aggarwal AN, Kumar R et al. Prevalence of bronchial asthma and association with environmental tobacco smoke exposure in adolescent schoolchildren in Chandigarh, north India. Journal of Asthma. 2001; 38:501-507.
[29] Doing GH, Ding HL, Ma YN et al. Effects of environmental tobacco smoke on respiratory health of boys and girls from kindergarten: results from 15 districts of northern China. Indoor Air. 2007; 17:475-483.

[30] Salo PM, Xia J, Johnson CA et al. Respiratory symptoms in relation to residential coal burning and environmental tobacco smoke among early adolescents in Wuhan, China: a cross-sectional study. Environmental Health. 2004; 3:14.

[31] Bearer CF. Environmental health hazards: How children are different from adults. The Future of Children. 1995; 5 (2):11-26.

[32] Regidor E, Gutierrez-Fisac JL, Calle ME, Navarro P, Dominguez V. Trends in cigarette smoking in Spain by social class. Prev Med. 2001; 33:241-8.

[33] Hutchinson SG, Penders J, Muris JWM, van Schayck CP, Dompeling E et al. Environmental Tobacco Smoke Exposure and Respiratory Complaints in Children Aged 0-13 Years: A Cross-sectional Study in South-Limburg. The Netherlands Journal Aller Ther. 2013; S11: 002.

[34] Maziak W, Ward KD, Eissenberg T. Measuring exposure to environmental tobacco smoke (ETS): a developing country's perspective. Preventive Medicina. 2006; 42:409-414.

[35] Best CM. Parental smoking and increased risk of child malnutrition among families in rural Indonesia. Tob. Control. 2008; 17: 38-45.

[36] Bolte G, Fromme H. For the GME Study Group. Socioeconomic determinants of children's environmental tobacco smoke exposure and family's home smoking policy. Europe Journal Public Health. 2009; 19:52-58. 